James, N and Busher, H (2006) Credibility, authenticity and voice: dilemmas in online interviewing Qualitative Research 6 (3) 403-420

\title{
Credibility, authenticity and voice: dilemmas in web-based interviewing
}

Authors' Biographical Notes:

Dr Nalita James is a lecturer in the Centre for Labour Market Studies, University of Leicester. Her research interests are learning and work identities, specifically in relation to higher education, informal learning and the use of theatre and the application of online research methods particularly the use of electronic mail.

Dr Hugh Busher is a senior lecturer in the School of Education, University of Leicester. His research interests are the development of more inclusive education through use of appropriate pedagogy; leadership, cultures, and the micro-politics of change in schools in particular socio-political contexts; and the developing workfocused identities of teachers, other staff and students mainly in schools.

Address for correspondence: Dr Nalita James, Centre for Labour Market Studies, University of Leicester, 7-9 Salisbury Road, Leicester, LE1 7RF, UK. Tel: +44 (0)116 252 5957; fax: +44 (0)116 2525953 email: nrj7@leicester.ac.uk

Word Count: 7857 


\title{
Credibility, authenticity and voice: dilemmas in web-based interviewing
}

\begin{abstract}
This paper explores the methodological issues encountered when using email as a web-based interview in on-line qualitative research. By drawing on two separate research studies that used this method to explore participants' understandings of their professional experiences and developing professional identities, the researchers consider the methodological implications in using this approach. These include issues affecting the credibility and trustworthiness of the research design of the studies and issues around the authenticity of participants' voices and how that was affected by power and control in the interview process. Despite these dilemmas, the paper recognises the contribution that web-based approaches can make to research by allowing researchers to hold asynchronous conversations with participants, especially when they are distant from the researcher, and to generating reflective, descriptive data. It leads us to conclude that it is worth refining our methodological framework to strengthen the trustworthiness and credibility of future research studies that use email.
\end{abstract}

Keywords: Web-based, email, interviewing, authenticity, credibility, conversations 


\section{Introduction}

Recently there has been a growth in the literature on the use of the web as a primary tool for conducting research. In particular, the work of Mann and Stewart (2000) has provided details of many studies by researchers who have used web-based qualitative methods to collect in-depth data. For example approaches such as focus groups, chat rooms and conferences have been used to explore on-line experiences in synchronous real-time (O'Connor and Madge 2001, Eichorn 2001). Amongst other aspects, this literature has explored the methodological possibilities of email as a medium for online research in asynchronous non-real-time. Now there is interest in its methodological development to support qualitative approaches in educational research (Foster 1994, Russell and Bullock 1999 and Henson et al 2000) and organisational research (Morgan and Symon 2004).

In this paper we intend to contribute to this development, by exploring the methodological issues we encountered when using email as a medium for qualitative interviewing. By drawing on two separate small scale research studies with tertiary level educators that used email interviewing to explore participants' understandings of their professional experiences and developing professional identities we consider two key areas: the establishment of credibility throughout the research process (Lincoln and Guba 1985) and the authenticity of the voices of the participants in terms of power and control in the interview process. Using email interviewing led us to question whether the procedures we had used addressed sufficiently these key parameters of qualitative research. None the less the opportunities for holding asynchronous conversations with distant participants through email and the reflective 
data that can be generated, drew us to conclude that it is worth refining these procedures to strengthen the credibility and trustworthiness of such studies using this method.

\section{Methodological Considerations in Qualitative Web-based Research}

In drawing on our experiences of using email interviewing, both our studies explored participants' understandings of their professional experiences and developing professional identities, but in different contexts. One of the studies focused on the reflections of nine psychology lecturers and the construction of their professional identities both as teachers in higher education and within the main communities in which they worked. Interviewing emphasised the experiential (Connelly and Clandinin 1986) and was intended to explore the developing professional stories that became the basis for their professional identities, as well as exploring their understandings of their experiences as lived and told stories. They were invited to comment on: the images they used to construct professional identity and shape professional practice; the way in which professional identity was managed within the communities in which they lived and worked; the values and knowledge-base of their work as teachers; and how fundamental these communities were to their teacher professionalism.

The other study focused, through semi-structured interviews, on ten adult educators who were doctoral students and their views on coming to terms with being part-time students following an extended campus programme of study of an English university. 
They were asked to reflect on the excitements and concerns of being a student and how these were shaped by underlying cultural conflicts between the expectations of their own cultural milieux, which they experienced in their everyday lives, and those of the university they attended, albeit as part-time students; on their relationships with their tutors as mediators of university custom and practice and gatekeepers to the academy; and on their developing identities as doctoral level students. Bourdieu et al (1994) explored the experiences of students in a French university and how they experienced the process of becoming students and learning the discourses of successful practice through their encounters with the university system, especially as it was mediated by their tutors. This recognized that how students' made sense of their experiences is shaped by the tensions they experience between their powerlessness as students, their wish to be successful in gaining membership of a particular academic discourse community and the power located in a university system. In this study participants' processes of sense making were further complicated because many of them used English as their second or third language, had never worked in the UK, and in some cases did not work in other institutions of higher education.

In carrying out our two independent studies we came to realise that our epistemological and methodological approach to the use of email interviewing shared some similarities. We both wanted a research method that could capture and reflect narrative accounts of participants' experiences and provoke their in-depth reflection of their understandings of their developing professional experiences and identities (Busher 2001, James 2003). 
In constructing our studies, we considered the suitability of different types of qualitative interviews in terms of their design and ethics. Face-to-face interviewing offered us a template with its processes for gaining consent and guaranteeing confidentiality as well as the flexibility to gather data through the use of open questions and follow-up discussion (Chen and Hinton 1999). However, our participants were located at a distance from us within and outside the UK. So we had to overcome the practical constraints (for example costs associated with travel, venue, data transcription) of conducting the interviews necessary for our studies in a manner that replicated as closely as possible, given these constraints, the normal processes of qualitative face-to-face interviewing.

We considered telephone interviewing as an alternative approach since, such interviews can be used to access hard-to-reach participants (Sturges and Hanrahan, 2004). However, in one study, the different time zones between participants and researcher would have made it difficult to agree a convenient time for conversations. Further, a key issue for us was the quality of data that we would collect because, as Arksey and Knight (1999) note, the medium of telephone interviewing can generate short answer responses in interviews, not the in-depth descriptive and reflective accounts that we were trying to elicit and hence, did not seem appropriate for our studies.

Email interviewing, we thought, was a medium that would allow us to facilitate indepth interviews, especially as all our participants had ready access to email and were familiar with using it in their professional lives. An asynchronous email exchange, as Henson et al (2000) discovered, encourages participants to explore and revisit their 
insights into their developing professional identities, allowing them to move back and forth through their narratives, thinking about their responses, drafting and redrafting what they want to write (Mann and Stewart 2000), creating, in effect a form of enriched interview.

Email also offered us the opportunity to 'interview' participants individually, necessary for exploring their discrete views of their developing professional identities and life histories in a variety of different macro and organisational cultures. Duranti (1997) and Cazden (2000) suggest that people with different social, cultural and organizational experiences, respond differently to questions about their professional life stories. Street (1995), too, has argued that people's understanding of their identities and communities, their construction of social literacies, are affected by their cultural locations. So group interviews constructed through web-board discussions did not seem a relevant research tool.

\section{Establishing credibility and trustworthiness}

Researchers such as Lincoln and Guba (1985), Denzin and Lincoln (2000) and Flick (2002) have pointed to the need for qualitative researchers to be as vigilant as positivist researchers about ensuring the validity and reliability of their studies, even if they choose to use other terms such as credibility and authenticity, to describe the qualities that establish the trustworthiness of their studies. The design of these studies drew on conventional approaches to interview-based qualitative research to guide conversations between a researcher and other participants in a study. Such interviews 
use a format that is either semi-structured or unstructured (Bryman, 2001). The questions we asked of participants in our studies were supplemented by probes to explore and gain a deeper understanding of issues as did Beattie (1995) in her research. These approaches were enhanced by us encouraging participants to explore and revisit their insights into their developing professional identities by thinking about their responses, and drafting and redrafting what they wanted to write as some of our participants noted in Table 1 below. One participant reflected that the process had made her wonder about the origins of her professional identity as a researcher/ psychologist and was grateful for the time our questions had permitted her to use to think about this.

[Insert Table 1 here]

The iterative process of these interviews - that constantly reflective process that Hammersley (1998) commends as a safeguard for qualitative researchers against the risk that they might unwittingly fall short of the rigorous standards of probity that is required - also guarded against aspects of the interviews remaining underdeveloped. So points that had been seemingly overlooked or only briefly responded to during early parts of our interviews were able to be revisited later in the course of a conversation. Although participants may not have given a particular response at one point in time, it did not mean that they were unaware of that issue in the exploration of professional identity or unable to write about it, merely that they chose not to do so at that particular point in the flow of the conversation. McCulloch et al (2000) took the view on this that '...all that can be said is that the way the interview played out 
meant that the point was not spontaneously made at that time in that specific setting. At another time, in another interview, the point might have been made' (p.122).

\section{Consent, confidentiality and collaboration}

We were concerned to ensure that the research processes were conducted in an ethical manner (BERA, 2004) with participants giving us their informed voluntary consent to being involved with useful research that used processes of data collection and interrogation that protected their privacy. Neither the voluntary nature of the consent nor the protection of privacy was unproblematic. The latter involved us in thinking very carefully about how we kept records of our participants' conversations. As Thach (1995) comments, the open nature of electronic networks makes it more difficult to ensure participants' anonymity. Email systems automatically send participants' addresses along with their responses, so users are instantly visible.

To assuage putative participants' fears about protecting their privacy we sent them rubrics about how the research would be conducted (see Tables $2 \mathrm{a}$ and $2 \mathrm{~b}$ below) when seeking their informed consent to participate in the study. None the less, whilst not questioning our integrity as researchers and our efforts to safeguard confidentiality, some participants expressed concerns about the risk of email communications being passed on inadvertently to other parties. The need for privacy in our studies meant we could not send our participants a single group communication for each question of our semi-structured interview schedules, since this might reveal 
participants' identities to each other. This neutralised one of the key advantages of email: communicating with many people at once.

[Insert Tables $2 \mathrm{a}$ and $2 \mathrm{~b}$ here]

The voluntaristic nature of our participants' consent was problematic because we knew our participants professionally before we began these studies. Although we thought this would facilitate their willingness to engage with our projects - and there is evidence in participants' interviews that it did - our positions in our organisations relative to our participants, especially in the case of the doctoral students, challenged the nature of voluntarism. In the latter case in particular we feared that, as the researcher was a tutor on their course, the asymmetrical power relationships that Bourdieu et al (1994) noted between tutors and students would spill over into the research arena, inhibiting participants' responses as well as their choice of whether or not to participate. That some putative participants did refuse to join the study when approached, and others dropped out early in its course suggested that voluntarism and self-interest rather than fear of the power of the tutor as gatekeeper to the academy was probably the main reason for them participating.

Collaboration took various forms since, as educators, participants and ourselves were professionally interested in the processes and outcomes of this research. One form of collaboration was through the record keeping processes of the studies. Given the limited research methods literature on email interviewing, we adapted conventional frameworks of qualitative research to meet the needs of the new medium (see Tables $2 \mathrm{a}$ and $2 \mathrm{~b}$ above). The records of our conversations - akin to the tape-recorded 
records of face to face interviews - were not erased as the emails bounced back and forth between the researchers and the other participants, and were kept intact in the chronological sequence of the discussions. This enabled participants' and researchers to reflect in an iterative manner on their developing conversations and, in due course, allowed participants to consider the accuracy of the texts of our conversations, establishing the authenticity of them.

Another form was in the research relationships we set out to build, engaging both the researchers and participants, as Oakley (1981) noted, beyond stereotypic roles of question-asking and question-answering. We thought that this approach would lead to greater disclosure, mutuality and reciprocity between the researcher and the participants so that we could, '...acquire an understanding of the participant's perspective through open and honest dialogue...' (Anderson and Kanuka 2003, p.88). Lebesco (2004), too, found that a collaborative approach helped her to gain rapport with her participants. Markham (2004) points out, '...methodologically we should not ignore this feature because as interaction constructs and reflects the shape of the phenomena being studied, interaction also delineates the being doing the research in the field' (p.147). As the interviews developed, the participants began to take greater ownership of the processes of narrative construction by responding to our questions in unexpected ways and directions. As researchers, we responded to the new directions of their narratives by asking further questions about their texts rather than sticking to the agenda of the original interview schedule which would have enforced our control of the interview process. 
Our pre-existing professional relationships with participants made it less necessary for us to build a scaffold for developing trust, needed if participants are unknown to researchers. The depth of participants' responses to our questions might have been attributable to this prior interpersonal knowledge, as in Wicksteed's research (2000). The participants' lack of inhibition and frankness, like those in the study of HolgeHazelton (2002), which emerged in their more personal narratives and were bound up in dimensions of their lives, might also have been a consequence of these pre-existing relationships. One commented on how she coped with what she perceived as the contradictions of her professional identity, especially now she had applied for early retirement. This challenged her to consider how she might then signify her identity when she no longer had the framework of her professional work. However, this level of self-exposure also reinforced the participants' authentic behaviour (Mann and Stewart 2000).

One of the problems facing researchers using interviews is that the outcomes of conversations can be distorted because people interpret the social characteristics of the other, such as age, race, gender and organisational status, to shape their responses to fit whatever pattern of sense making seems to be being required of them (Sproull and Kiesler, 1986, Mann and Stewart 2000). Researchers' values and attitudes can be conveyed to participants not only by researchers' social characteristics but also by their non-verbal and verbal cues. On the face of it, email hides many of these personal and social characteristics (Thach, 1995). However as we were already known to our participants the shield which email might have provided (Mann and Stewart, 2000) against the influence of these factors was ineffective. 
If the presence of social signals is problematic for participants and researchers in interview-based research, so is their absence. We recognised that the nonverbal and contextual elements that are seen as essential to the interviewing process (Anderson and Kanuka 2003) would be absent in our studies because of using text-based interactions. The lack of personal contact inherent in the email interview process was commented on adversely by some participants. Slow responses by the researchers to participants' queries about the research process or the meaning of some questions, seemed to further weaken participants' sense of some ownership of the research conversations (see Tables $2 \mathrm{a}$ and $2 \mathrm{~b}$ above). These factors tended to deprive participants of a sense of engagement in a human conversation and of a sense of security of knowing, even if incorrectly, who a researcher is socially, making them less willing to continue in the research conversations.

This points to the importance of the socio-emotional aspects of interviewing and as Knight and Saunders (1999) comment, on the need for researchers who engage in web-based research to use different ways to build trust and to encourage participants to 'open up.' Paccagnella (1997) suggested that on-line research can identify the existence of '...strategies of visibility... which make up for the lack of traditional social cues and which indeed permit the development of a status differentiation...' However, such strategies do not seem to be as powerful in shaping conversations as the social presence of a researcher with participants. In one study, the absence of visual cues seemed to make it easier for some participants to start and terminate their interviews as and when it suited them despite text-based cues such as: 'Haven't heard from you in a while. I wondered if you still wished to continue the interview?' from the researcher. 
Presentation and power: Whose voice is it anyway?

Of major importance in interpretative research is that of clarifying whose voices are heard, those of the participant(s) or that of the researcher, and of establishing that participants' voices are heard clearly and reflect accurately the views they hold. As Gatson and Zweerink (2004) remark, the 'management of presence and presentation' (p.191) are crucial in the conduct of research. In both our studies this was problematic because of the pre-existing relationships between researchers and participants. In one study in particular this was problematic because the researcher was also a tutor for participants' doctoral studies. Other researchers, such as Lincoln and Guba (1985), Denzin and Lincoln (2000) and Flick (2002) have pointed to the need for qualitative researchers to be vigilant in ensuring the authenticity of the voices of their participants.

One concern we had was that the interview responses of the participants might not have been entirely their own thoughts (Chen and Hinton 1999). We assumed that because our participants responded to us on their usual email addresses that it was they who were responding - but we had no visual evidence of that as a researcher would have in a face-to-face interview. Had we 'cold-called' this would have made it difficult for us to know whether the online identity presented to us was that of the participant or an invented alias, or another person using somebody else's email address. 
Another concern was that, despite our efforts to engage the participants in agreeing the accuracy of the records of their conversations and reflecting on the credibility of our interpretations of these conversations, we were never entirely sure to what depth the participants had actually agreed to these records. For example, one participant pointed out that 'in email communication clarification is not always easy' especially if there are time lapses in message exchanges and participants could not remember what they had said previously. However, the linkage between the participants' voices and the researchers' interpretations of the themes emerging in them was reflected in the conceptual models that emerged from our studies (see Busher 2001 and James 2003 for a more detailed methodological account).

A third concern was how to develop participants' reflexivity with their texts. Asking participants in a study to reflect critically on their narratives helps researchers not only to authenticate participants' accounts but also to develop a greater understanding of the phenomena being studied (Seale, 1999). It also helped our participants to revisit issues that they considered important but had slipped temporarily out of view (Russell and Bullock 1999). We tried to give our participants' the experience of engaging in an iterative discussion of their changing professional lives in a variety of organisational cultures through varying presentations of the self, rather than by either the researcher's questions alone or the participants' concerns (Cooper and MacIntyre 1996). Consequently, the records of the conversations were constantly under review and being authenticated as each new question and its responses were added to the existing record of the email trail. 
However, this degree of reflection also generated a different issue for us: to what extent did the moderated and modified reflections of participants' on their experiences generate an authentic account of those experiences and of how participants made sense of them? As Mann and Stewart (2000) have also reflected, did the time for reflection provide a 'safeguard' because our participants were able to edit the text to convey the meanings they really intended?

The construction of professional identity includes a dimension of complexity and fluidity (Giola and Thomas 1996). It is inextricably linked with who we are, our commitments and values and is 'integral and continuous' (Kendal 1999). As Mann and Stewart (2000) remark, 'For this reason it is seen to be difficult to sustain a persona which is quite divorced from the "real" self" (p.210). Processes of reflection on personal texts and narratives do not only happen in interviews and on-line exchanges but in everyday life, too. People tend to review and rewrite their histories and perspectives in the light of their developing experiences. So to this extent, encouraging participants to reflect on their views did not necessarily undermine the authenticity of their accounts. Indeed, it may have enriched them so long as we were careful to avoid, intentionally or unintentionally, indicating what sort of answers we were seeking through the way we constructed our questions.

A fourth concern was our power as researchers to control the flow and development of the interviews. Naively, when we began our studies we thought 'email brings people into contact ... and places each on equal ground' (Boshier, 1990, p.51) and considered email had the potential to democratise narrative exchanges (Illingworth, 2001). As the interviews progressed we began to wonder whether email did indeed 
democratise the process of research by creating a more equitable process of social interaction between researchers and participants.

At the start of our interviews we were in more powerful positions epistemologically than were our participants, not least because we shaped the agenda of the discussions and had access to the relevant literatures underpinning the conceptual frameworks of the studies (Easterby-Smith et al, 1991). We were also in more powerful positions bureaucratically because, as Carter (1993) pointed out, we created the organisational structures of the studies by providing the interview schedules and the 'rules of engagement' as discussed above.

Despite our fears that we might be exerting undue overt and covert control of the research process, through time it became apparent that the participants exercised influence, too. Interviews that had been scheduled by the researchers to take a matter of two to three weeks eventually extended in many cases over several months, because this speed of responses suited participants in the busy press of their daily lives (see Table 1 above). The medium of email allowed them this control over the research dialogues. It slowed up the whole research process considerably, despite many requests from the researchers in the early phases of the interviews for participants' to respond within three working days. In face-to-face interviews researchers are able to exert greater control, usually being able to keep conversations to a pre-determined agenda and prevent them extending beyond their allotted time, if not to prevent participants curtailing interviews because of other social or workrelated pressures. 
Some participants initially apologised profusely for being late with their answers, indicating their acknowledgement of the power they perceived the researchers as having in controlling 'their' research projects, into which the participants had been invited. Gradually, however, researchers and participants alike came to accept these 'delays' as the normal, if unexpected pace of this email based research process. It was markedly different from the rhythm of the semi-structured face-to-face research conversations (Robson, 1993) that we were trying to mimic online. Indeed we eventually came to discover like Russell and Bullock (1999), that an exciting element of the process was that we never quite knew when we were going to get a response from whom. It also released our time for pursuing our other professional duties, which did not really allow us to sustain the time schedule for the research dialogues that we had set.

Prompt replies, we discovered, were not actually necessary, particularly when slower ones gave opportunity for more powerful reflection on the main focus of the studies. Like Selwyn and Robson (1998) we discovered that asynchronicity was an attractive and creative feature of email interviewing. The shift in power, from researcher driven semi-structured interview schedules to a more collaboratively constructed one that was responsive to participants' needs for using time, also turned out to be fruitful in improving the quality of participants' reflections. We noticed that participants who did not respond immediately tended to generate more thoughtful answers and insights on the construction of their professional identities, as one researcher reflected in a research diary. A participant commented: 
'I didn't email you straight back, because I was thinking about my answer. So my responses were more carefully thought through and probably longer than if I'd tackled the whole thing in a face-to-face interview ... This is what's good about the email process ...'

As the process of interviewing became more naturalistic (Robson 1993), so, perhaps unsurprisingly, the richness of the narratives increased. In other ways, too, participants gradually took more control over the direction of the agenda, by responding and reflecting further on particular points during the interviews, leaving us merely to moderate them. It allowed participants to elaborate their own thinking about those aspects of professional identity that were important to them (see Table 1).

However this strengthening of participants' control raised the potential risk of the interviews having an increasingly selective focus (Connelly and Clandinin, 2000) and the risk that important points might not be fully discussed or poorly developed, as the routes the conversations took became ones we had not originally anticipated. The interview schedules remained as aide-memoires to help us to avoid such narrowing of foci. The changing nature of these interviews through time, as semi-structured interviews subtly merged into unstructured approaches, highlights the difficulty of clinically categorising research methods, and shows how control of the research process slipped from the grasp of the researchers, at least to some extent.

\section{Conclusion}


The email based research interviews were set up in a semi-structured format to pursue a specific agenda that had been pre-selected by the researchers in order to gain a deeper understanding of the issues in which we were interested, although they eventually developed a more egalitarian shape of conversations between fellow professionals. Like Beattie (1995), our conversations with participants made use of some of the specific features of email, such as the possibility of asynchronous conversations and the capacity to track conversations and reflect on a continuous developing record of them, to encourage extensive reflection by participants' on their professional experiences.

The feature of asynchronicity facilitated the exploration of busy professional participants' reflections on their lives and identities in the midst of their experiences. It enabled participants, who might not otherwise have been able to take part in a study to do so, as Bampton and Cowton (2002) also remarked in their research. Through the creation of on-line narratives we were able to gain access to the stories of their experiences and their reflections on those. The development of these reflexive discourses improved serendipitously as we relinquished some of our control of the interview schedules. This allowed participants to take greater ownership of their narratives by being able to alter the shape and structure of them to fit more closely with their own constructions of reality. That they were able to pursue this at a time and space convenient to them through the medium of email led, we believe, to richer stories.

The continuous and visible record of the email interviews in every exchange enabled participants to revisit issues that had slipped temporarily out of view through the 
course of their interviews (Russell and Bullock 1999), because they could return to earlier aspects of the interview at their convenience and remind themselves of their earlier interpretations of their lives. As illustrated earlier in this paper, this seems to have provoked a richness of reflection among the participants in both studies beyond what we would have expected had we pursued rigorously semi-structured interview schedules and not allowed participants to develop their own narratives in ways that were meaningful to them. Morgan and Symon (2004) too noted that, '...this potential increase in reflexivity...may be considered to be a very positive aspect of the medium... 'because it makes the socially constructed nature of "reality" more transparent' (p.31). The iterative discussions on the developing texts of the interviews also allowed us to interrogate the authenticity of the participants' voice. None the less, there remains the possibility that participants may not have been who they claimed to have been in the email conversations. The only evidence we had to assuage our fears on this came from our prior knowledge of our participants in other professional contexts.

Although, then, we are convinced of the authenticity of the voices we heard from our participants, like Kendal (1999) we would contest the claim that email democratises research conversations - it might shift the balance of power between researcher and researched to some extent, but researchers cannot escape from the power they exert from structuring the rules of the process. Nevertheless, email as a medium does hand some levers of control for engaging in the research process to participants. For example, the lack of an embodied social presence of the researcher in the conversations makes it easier for participants to ignore researchers' requests. It lends support to Giddens (1984) theory of structuration that power is exerted by influential 
people not only through control of systems and resources but also through control of the rules for engaging with systems and resources.

The quality of interpersonal relationships was crucial in these studies, as it is in any qualitative research. Whilst recognising our presence as on-line researchers, we found this never compromised our participants' willingness to participate in our studies. As already indicated, in our studies we knew the participants beforehand as fellow professionals, allowing us to build on pre-existing relationships of trust and develop open and honest dialogue. However the medium of email hides most conventional social signal systems and seems to weigh the balance of power in email exchanges strongly towards the originator, in this case the researcher. So participants' responses may be cursory, disclosing as little of themselves as they think reasonable within the framework of what they have agreed to in an uncertain environment, as they tend to be with telephone interviews (Arksey and Knight 1999). It forces researchers to think very carefully about how they build relationships of trust with participants they cannot see and may never meet. It raises questions, and prompts us to undertake further research to explore how participants who do not have prior knowledge of the researchers would react if invited to partake in similar web-based qualitative research projects. Problematic, then, is the extent to which it is possible to build collaborative conversations and trust, allowing participants to feel able to explore topics in depth, when many of the normal social signal systems are absent from the conversations.

Establishing the credibility of these studies was achieved through adapting conventional approaches to qualitative research to the particular features of email as a medium of communication. This raised particular concerns about conducting the 
studies in an ethical manner because of the capacity of email to make participants visible. It also posed problems for ensuring that records of conversations were properly preserved and in such a state as participants would be able to comment on the accuracy with which they reflected their views. This latter was resolved by constructing rubrics to guide researchers and participants in the manner of collecting and safeguarding exchanges. Despite the dilemmas faced by us as researchers with this medium of email based qualitative research, we concur with Sturges and Hanrahan (2004) that ' ... advances in technology shape the way we do research, and researchers need to consider how the technology fits in the lives of potential participants' (p.116). In particular, we are encouraged to continue to explore its potential especially for more reflective in-depth interviewing such as might be used in life history methods. It has most to offer as a medium when face-to-face contact between researchers and participants is either unnecessary or impractical, and when snappy responses to research questions are not required.

\section{References}

Anderson, T. and Anuka, H. (2003) e-Research. Methods, Strategies and Issues, Boston: Ablongman. 
Arksey, H. and Knight, P. (1999) Interviewing for Social Scientists, London: Sage Publications.

Bampton, R. and Cowton, C.J. (2002) 'The E-Interview,' Forum: Qualitative Social ResearchAvailable online at: http//www.qualitative-research.net/fqs/fqs-eng.htm, 3 (2).

Beattie, M. (1995) Constructing Professional Knowledge in Teaching. A Narrative of Change and Development, New York: Teachers' College Press.

BERA (2004) 'Revised Ethical Guidelines for Educational Research,' British Educational Research Association, April 2004.

Boshier, R. (1990) 'Socio-psychological Factors in Electronic Networking,' International Journal of Life-Long Education, 9(1): pp.49-64.

Bourdieu, P., Passeron, J.C. and de Saint Martin, M. (1994) Academic Discourses, Cambridge: Polity Press.

Bryman, A. (2001) Social Science Research Methods. Oxford: Oxford University Press.

Busher, H. (2001) Being and Becoming a Doctoral Student: Culture, Literacies and Self-identity, TESOL Arabia Conference, 14-16 March 2001. 
Carter, K. (1993) 'The Place of Story in the Study of Teaching and Teacher Education,' Educational Researcher, 22, pp.5-18.

Cazden, C. (2000) 'Taking Cultural Differences into Account,' In B. Cope, and M. Kalantis, (eds.) Multi-literacies: Literacy, Learning and the Design of Social Futures London: Routledge.

Chen, P. and Hinton, S.M. (1999) 'Realtime Interviewing using the World Wide Web, Sociological Research 4 (3). Available online at: http://www.socresonline.org.uk/socresonline/4/3/chen/html

Clandinin, D.J. and Connelly, F.M. (2000) Narrative Inquiry: Experience and Story in Qualitative Research, San Fransciso: Jossey Bassey)

Connelly, F.M. and Clandinin, D.J. (1986) 'On Narrative Method. Personal Philosophy and Narrative Unities in the Story of Teaching,' Journal of Research in Science Teaching, 23 (4): pp.293-310.

Cooper, P. and McIntyre, D. (1996) Effective Teaching and Learning: Teachers' and Students’ Perspectives, Milton Keynes: Open University Press.

Denzin, N.K. and Lincoln, Y.S. (eds) (2000) Handbook of Qualitative Research, $2^{\text {nd }}$ edn, London: Sage Publications.

Duranti, A. (1997) Linguistic Anthropology, Cambridge: Cambridge University Press. 
Easterby-Smith, M.R., Thorpe, R. and Lowe, A. (1991) Management Research: An Introduction, London: Sage Publications.

Eichorn, K. (2001) Sites Unseen: Ethnographic Research in a Textual Community, Qualitative Studies in Education, 14 (4): pp.565-578

Flick, U. (2002) An Introduction to Qualitative Research, $2^{\text {nd }}$ edn, London: Sage Publications Ltd.

Foster, G. (1994) 'Fishing with the Net for Research Data,' British Journal of Educational Technology, 25 (2): pp. 91-97.

Gatson, S.N. and Zweerink, A. (2004) 'Ethnography Online: "Natives" Practising and Inscribing Community,' Qualitative Research, 4(2):pp.179-200.

Giddens, A. (1984) The Constitution of Society: Outline of the Theory of Structuration, Cambridge: Polity Press in association with Basil Blackwell.

Giola, D.A. and Thomas, J.B. (1996) Identity, Image and Issue Interpretation. Sense Making during Strategic Change in Academia, Administrative Science Quarterly, 41:pp.370-403.

Hammersley, M. (1998) Reading Ethnographic Research: An Ethical Guide, London: Longman. 
Henson, A. Koivu-Rybicki, V., Madigan, D. and Muchmore, J.A. (2000) Researching Teaching through Collaborative Inquiry with Outside Researchers, in A. Cole, A. and J.G. Knowles (eds.) Researching Teaching: exploring Teacher Development Through Reflexive Inquiry, Boston Ma: Allwyn and Bacon,pp.186-197

Hewson C. (2003) 'Conducting Research on the Internet,' The Psychologist, 16, (6):pp. 290-293.

Holge-Hazelton, B. (2002) 'The Internet: A New Field for Qualitative Inquiry?' Forum: Qualitative Social Research, 3 (2). Available online at: http://www.qualitative-research.net/fqs/

Illingworth, N. (2001) The Internet Matters: Exploring the Use of the Internet as a Research Tool, Sociological Research Online, 6 (2). Available online at: http://www.socresonline.org.uk/6/2/illingworth.html

James, N.R. (2003) Teacher Professionalism, Teacher Identity: How Do I See Myself? Unpublished Doctorate of Education Thesis, University of Leicester, School of Education, July 2003.

Kendall, L. (1999) Recontextualising Cyperspace: Methodological Considerations for Online Research, In S.Jones (ed.) Doing Internet Research, Thousand Oaks: CA and London: Sage Publications, pp.57-75. 
Knight, P.T. and Saunders, M. (1999) 'Understanding Teachers’ Professional Cultures through Interview: A Constructivist Approach,' Evaluation and Research in Education, 13(3); pp.144-156.

Lebesco, K. (2004) Managing Visibility, Intimacy, and Focus in Online Critical Ethnography, in M.D. Johns, S.L.S. Chen, and G.J. Hall (eds) Online Social Research: Methods, Issues and Ethics, Oxford:Peter Lang Publishing, pp.63-80.

Lincoln, Y.S. and Guba, E.G. (1985) Naturalistic Enquiry, London: Sage Publications.

McCulloch, G. Helsby, G. and Knight, P. (2000) The Politics of Professionalism: Teachers and Curriculum, London and New York: Continuum.

Mann, C. and Stewart, F. (2000) Internet Communication and Qualitative Research. A Handbook for Research Online, London: Sage Publications.

Markham, A.N. (2004) Representation in Online Ethnography, in M.D. Johns, S.L.S. Chen, andG.J. Hall (Eds) Online Social Research: Methods, Issues and Ethics, Oxford: Peter Lang Publishing, pp.141-157.

Oakley, A. (1981) 'Interviewing Women: A Contradiction in Terms,' in H. Roberts,(ed.) Doing Feminist Research, London: Routledge, pp.30-61. 
Paccagnella, L. (1997) 'Getting the Seats of your Pants Dirty: Strategies for Ethnographic Research on Virtual Communities,' Journal of Computer-Mediated Communication, 3 (1), Available online at: $\underline{\text { http://www.ascusc.org/jemc/vol3/issue1/paccagnella.html }}$

O’Connor, H. \& Madge, C. (2001) 'Cyper-parents and Cyber-research: Exploring the Internet as a Medium for Research,' 5 (4), Available online at: http://www.socresonline.org.uk/5/4/o'connor.html

Rizk, N. (2003) Technological Assistance in Survey Research: Productive Face to Face Interview, CBLIS conference, University of Cyprus, July 2003.

Robson, C. (1993) Real World Research. A Resource for Social Scientists and Practitioner-researchers, Oxford: Basil Blackwell.

Russell and Bullock (1999) 'Discovering our Professional Knowledge as Teachers: Critical Dialogues about Learning from Experience,' in J. Loughran (ed.) Researching Methodologies and Practices for Understanding Pedagogy, New York: The Falmer Press.

Schmidt, W.C (1997) 'World-Wide Web Survey Research: Benefits, Potential Problems, and Solutions,' Behaviour Research Methods, Instruments and Computers, 29 (2): pp.274-279. 
Seale, C. (1999) 'Quality in Qualitative Research,' Qualitative Inquiry, 5, (4): pp.465478.

Selwyn, N. and Robson, K. (1998) Using Email as a Research Tool, Social Research Update, Guilford: Department of Sociology, University of Surrey.

Sproull, L. and Kiesler, S. (1986) 'Reducing Social Context Clues: Electronic Mail in Organization Communication,'Management Science, 32, pp.1492-1512.

Sturges, J. E. and Hanrahan, K.J. (2002) 'Comparing Telephone and Face-to-Face Qualitative Interviewing: A Research Note,' Qualitative Research, 4(1):pp.107-118.

Thach, L. (1995) The Use of Electronic Mail to Conduct Survey Research, Educational Technology, March-April 1995, pp.27-31.

Weber, S. (1986) 'The Nature of Interviewing,' Phenomenology and Pedagogy, 4 (2): pp.65-72.

Wicksteed, A. (2000) 'Manifestations of Chaos and Control in the Life Experiences of Individuals with Eating Disorders: Explorations through Qualitative Email Discourse,' Feminism and Psychology, 10 (4): pp.475-479. 
Table 1 Overview of Participant' Views of taking part in email-based research

(Both studies together $\mathbf{N}=19$ )

\begin{tabular}{|c|c|}
\hline Ad & es \\
\hline $\begin{array}{l}\text { Participants control when they can } \\
\text { respond } \\
\text { i.e. at own convenience ( } 4 \text { participants) }\end{array}$ & $\begin{array}{l}\text { Gap between sending questions led to: } \\
\text { Discontinuous responses (forgot what } \\
\text { had been said previously } \\
\text { participants); } \\
\text { Difficulty in getting clarification of } \\
\text { meaning of questions ( } 3 \text { participants) }\end{array}$ \\
\hline $\begin{array}{l}\text { More thoughtful/reflective answers } \\
\text { (11participants) } \\
\text { aided by being sent the questions one at a } \\
\text { time ( } 1 \text { participant) } \\
\text { That responses written (email) not spoken } \\
\text { (face-to-face) ( } 5 \text { participants) } \\
\text { Not responding straightway - delayed } \\
\text { response which can't be done in face-to- } \\
\text { face interviews ( } 2 \text { participants) }\end{array}$ & $\begin{array}{l}\text { Administering the email questions one } \\
\text { at a time led to: } \\
\text { Loss of coherence and flow of thought } \\
\text { (1 participant) } \\
\text { Concerns about how many questions - } \\
\text { unpredictability ( } 3 \text { participants) } \\
\text { Each question given full thought (1 } \\
\text { participant) } \\
\text { Email interviews are 'dry' because it is } \\
\text { more difficult to resolve intended } \\
\text { meanings of questions / answers than in } \\
\text { face-to-face } \\
\text { Misunderstanding the intent of the } \\
\text { questions and seeking immediate } \\
\text { clarification difficult ( } 3 \text { participants) }\end{array}$ \\
\hline
\end{tabular}




\begin{tabular}{|l|l|}
\hline $\begin{array}{l}\text { Distractions and disturbances of every } \\
\text { day life led to: } \\
\text { Responses not being as focused as in a } \\
\text { face to face interview (4 participants) } \\
\text { Losing threads of what the email } \\
\text { interview was about and getting more } \\
\text { from face-to-face interviews } \\
\text { participants }) \\
\text { Rapid responses (2 participants) }\end{array}$ \\
\hline
\end{tabular}

Source: Data drawn from both email studies (Busher 2001 and James 2003) 


\section{Table 2a Rubric for conducting interviews with doctoral students}

\section{Being and becoming a doctoral student: Reasons for carrying out this study}

This arises out of a real problem that I have observed over a number of years: The difficulties which new students have in adapting to the demands of doctoral studies in English universities. These difficulties seem to be compounded when the students are already experienced practitioners in their field, are part-timers, and have English as their second or third language. When the part-time students are based outside the UK and not in other institutions of Higher Education, then the problems of constructing a suitable work-related identity for pursuing doctoral studies in an English university seem very great.

This study seeks to explore how students construct their academic work-related identities and how their understandings of English for academic purposes, of the cultures of English universities and other universities, and of their own selves and future selves shape those.

Using email interviews for research is a relatively unknown field, so I am interested to explore it.

- As I cannot come easily to interview you and talk about the problem outlined above, I am trying to gather the data by email interview.

- If you are willing to be part of this study, please reply to this email straight away, confirming the appropriate confidential email address for this research. 
- Discussion with you will be in the strictest confidence and participants' names will not be revealed in any documents or papers developed from this research, or to any other participants in this research.

- You will be asked nine substantive questions, as well as a few biographical ones at the beginning, and a question evaluating this email research process at the end.

- The substantive questions will be sent to you one at a time for you to comment on and respond to. Each question may be followed up by supplementary questions. This process simulates a face-to-face semi-structured interview

- Please answer on top of the message and question sent to you (not at the bottom of it!). This is to sustain the sequence of question and answer in our discussion, without both of us having to scroll through screeds of earlier dialogue - although you are welcome to make reference to our earlier dialogue in you answers to current questions.

- Please do not delete any part of the email dialogue as it develops - it is your (and my!) record of our conversation

- Please reply to each communication within three days. 
- Our whole email discussion is expected to be completed within three weeks

- Many thanks for your help and time with this (pilot) project

Source: Busher, H. (2001) Being and becoming a doctoral student: Culture, literacies and self-identity, Paper presented at TESOL Arabia Conference, 14-16 March 2001. 


\section{Table 2b Rubric for conducting interviews with psychology lecturers}

A little while ago you completed a questionnaire, which focused upon professional identity, how it is managed within the professional environment and whether it is possible to generate a common sense of identity across the psychology profession. You agreed to take part in an email interview, which will address the issues raised in that questionnaire. Please read the following guidelines and if you are still happy to take part in the interview, please reply to this email and I shall send you the first question. The email interviews will consider the issues that arose in the questionnaire in more depth. The data gathered through the email interviews will provide a transcript of your account. These accounts will be used to inform the research study.

In undertaking the email interview please note the following guidelines:

i) If you are still willing to take part in this study, please reply to this email straight away.

ii) The interviews will be conducted in strictest confidence and your anonymity will be assured throughout the research project.

iii) You will be asked eleven substantive questions.

iv) These questions will be sent to you one at a time. Please respond to the question by email. Each question may be followed up by supplementary questions. 
v) It is anticipated that an ongoing dialogue will occur. In order to achieve this, please ensure that you answer on top of the message and question sent to you. PLEASE DO NOT ANSWER AT THE BOTTOM OF IT. This will ensure the sequence of questions and answers is not broken.

vi) Please do not delete any part of the email dialogue. This will be our record of the conversation.

vii) Please reply to each email question within three working days if possible. I will also try to reply to your response within that timescale.

viii) It is anticipated that the email dialogue will be completed within ten weeks.

ix) Once the dialogue is complete you will be asked to authenticate your account.

x) The completed dialogue may be followed up by further email discussion.

Source: James, N. (2003) Teacher professionalism, teacher identity. How do I see myself? Unpublished Doctorate of Education, University of Leicester, School of Education, July 2003. 